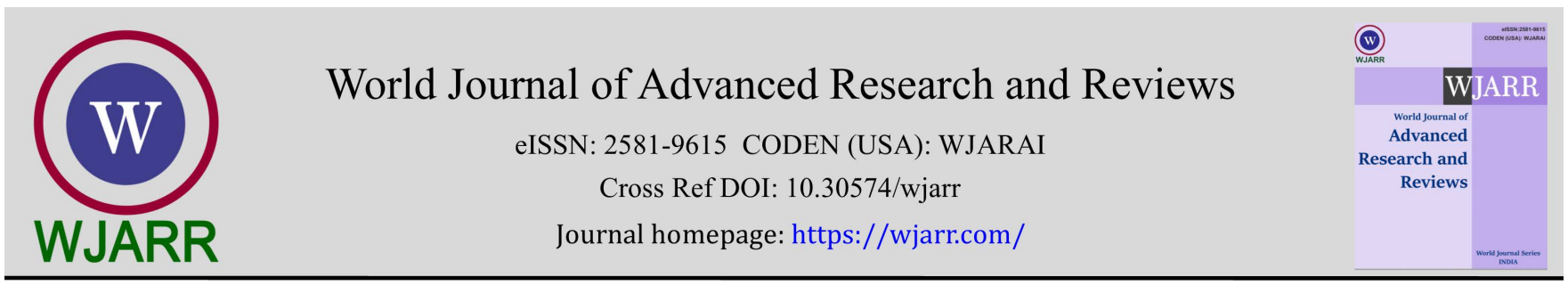

(REVIEW ARTICLE)

Check for updates

\title{
Genetic engineering of microalgae lipid biosynthesis for sustainable biodiesel production
}

\author{
Siti Zulaiha * \\ Faculty of Animal Science and Agriculture, Universitas Islam Negeri Sultan Syarif Kasim Riau.
}

World Journal of Advanced Research and Reviews, 2021, 11(03), 072-077

Publication history: Received on 24 July 2021; revised on 30 August 2021; accepted on 01 September 2021

Article DOI: https://doi.org/10.30574/wjarr.2021.11.3.0397

\begin{abstract}
Biofuel is one of the most promising alternative energy sources for reducing human reliance on fossil fuels. Microalgae has recently emerged as the most promising biofuel source. However, biofuels from microalgae are still not feasible to replace fossil fuels because of their high production costs, therefore, it is necessary to pick microalgae species with high growth rates and lipid content. Overexpression of lipid biosynthesis enzymes and inhibition of competitive metabolic pathways are two genetic engineering strategies that can be developed to assess microalgae lipid production. Malate and multienzyme enzymes (GPAT, LPAAT and DGAT) can be overexpressed in microalgae to boost lipid production. The strategy of blocking competitive metabolic pathways can be carried out through suppression of starch metabolism and lipid catabolism. The strategy of blocking competitive metabolic pathways has been carried out in several microalgae and is effective for enhancing lipid biosynthesis. Several mutations that block both the starch metabolic and lipid catabolic pathways can result in increased levels of microalgal lipid accumulation.
\end{abstract}

Keywords: Microalgae; Lipid biosynthesis; Overexpression of enzymes; Genetic engineering; Metabolic pathways

\section{Introduction}

Global climate change caused by greenhouse gas emissions from burning fossil fuels has become a threat to human life and all ecosystems on earth [1]. Currently, about $90 \%$ of global energy demand is met by fossil fuels which has caused several problems such as energy demand crisis and environmental damage [2]. With the increasing concern over this issue, the exploration for sustainable renewable energy sources is critical. Biofuels, which are produced from biomass, are considered as one of the most feasible energy alternatives to reduce human dependence on fossil fuels [3]. Biofuels have a number of advantages over fossil fuels [4], including sustainability, non-toxicity, biodegradability and reduced CO2 emissions [5].

Biofuels are obtained from natural resources. Biofuels are classified as first, second, or third generation biofuels based on the raw materials used in their production. Plants such as jatropha, almond, barley, camelina sativa, coconut, copra, peanuts, oats, rice bran, sesame, sunflower, sorghum, soybean, wheat, and karanja were used to produce the firstgeneration biofuels [6,7]. The production of biofuels from first-generation raw materials has been a source of controversy in recent years, owing to global food competition and ecological imbalances, as biofuel-based crops require a lot of area to grow [8]. Biofuel production is then carried on to the second generation, which is made from animal fat and waste biomass. However, this second generation of raw materials does not have a stable supply to meet future energy needs. To deal with this, microorganisms called third generation biofuels, can be employed as an alternative strategy. Different types of microorganisms have been identified as an absorber of ${ }_{\text {coz }}$ and can produce biofuels. These microorganisms are used to produce methane, biohydrogen, bioethanol and biodiesel by treating them under suitable biological conditions [9].

\footnotetext{
${ }^{*}$ Corresponding author: Siti Zulaiha

Faculty of Animal Science and Agriculture, Universitas Islam Negeri Sultan Syarif Kasim Riau. 
Biodiesel is one of the renewable fuels that has achieved tremendous success worldwide [10]. According to a World Bank report [11], 6.5 billion liters of biodiesel were produced worldwide in 2006, 75\% and 13\% of which were produced by the European Union and the United States, respectively. In recent times, the most promising raw material for biodiesel production is microalgae. Microalgae have advantages over other raw materials, such as high photosynthetic efficiency and the ability to grow 100 times faster than plants. Microalgae can produce 15-25 tons/hectare/acre of biomass, which is much higher than soybean ( 0.4 tons/hectare/year), rapeseed ( 0.6 tons/hectare/year), oil palm (3.62 tons/hectare/year) and jatropha plant (4.14 tons/ha/year) [12-15]. In addition, microalgae have a shorter harvest cycle (10-30 days) compared to conventional crops, which are usually harvested once or twice a year [16]. Biodiesel from microalgae biomass can also reduce $78 \%$ of $\mathrm{CO}_{2}$ emissions compared to traditional diesel fuel $[17,18]$.

However, despite the fact that microalgae as a feedstock can enhance biodiesel production, it is still not cost-effective enough to replace fossil fuels [19]. Microalgae species with a high growth rate and lipid content (>70\%) are required for the cost-effective generation of biodiesel from microalgae [9]. Therefore, it is necessary to increase the lipid content of microalgae to increase the economic value of biodiesel production. Nutrient restriction and various stress induction through various culture conditions in microalgae have been carried out to increase lipid content [20-22]. However, stress induction during cultivation can reduce the growth rate of microalgae and decrease lipid productivity [23]. As an effort to overcome this problem, the researchers studied genetic engineering techniques to increase lipid biosynthesis without reducing the growth rate of microalgae and lipid productivity.

The use of genetic engineering as a strategy for modifying microalgae strains for high lipid accumulation is very beneficial because these microalgae strains can be used for a long time and sustainably (without having to induce stress in every cultivation process) and reduce pollution when cultivated in open systems. Advances in knowledge of the full genome of several strains of microalgae and the identification of genes involved in lipid synthesis pathways have made genetic engineering a widely used strategy by researchers to increase lipid accumulation in microalgae [24,25].

Based on this rationale, the aim of this systematic review is to determine how to improve microalgae lipid production by overexpressing lipid biosynthesis enzymes and blocking competitive metabolic pathways.

\section{Genetic engineering to improve microalgal lipid biosynthesis}

Biochemical strategies such as nitrogen restriction [26], phosphate reduction, induction of high salinity stress [27] and addition of heavy metals such as cadmium [28], silicon reduction [29] and various other strategies have been used to induce lipid accumulation in microalgae. These stress conditions, on the other hand, can reduce the rate and yield of microalgae biomass, lowering lipid productivity [30]. Metabolic engineering is recognized as a viable and efficient technique for solving these difficulties by improving the content/accumulation and quality of lipids without impacting biomass yield.

The availability of tools for bioinformatics and knowledge of microalgae DNA sequences provided by genomic databases have allowed us to use microalgae as hosts for genetic engineering. Transformation of foreign genes into microalgae cells can be carried out by several methods [31] such as microprojectile particle bombardment [32], electroporation [33], mediated transformation by Agrobacterium tumefaciens [34], agitation in the presence of silicon carbide [35] and glass beads [36]. Overexpression of enzymes involved in lipid production and inhibiting a competitive metabolic pathway are two genetic engineering strategies for increasing the lipid content of microalgae explored in this paper.

\subsection{Overexpression of enzymes involved in lipid biosynthesis}

Lipid metabolism (biosynthesis of fatty acids and triacylglycerol) consists of several chemical conversion steps catalyzed by various types of enzymes. Acetyl-CoA carboxylase (ACCase) is the main enzyme involved in lipid biosynthesis and is most widely used for lipid enhancement studies in both plants and microalgae. Overexpression of this ACCase enzyme is one of the most successful strategies for increasing fatty acid synthesis in plants and microorganisms. Although microalgae have unique lipid biosynthetic pathways, such as the chloroplast pathway reported by Fan et al. in Chlamydomonas reinhardtii [37], the majority of enzyme pathways in microalgal lipid biosynthesis are similar to those found in plants [38]. As a result, using the ACCase enzyme overexpression approach to increase the quality of microalgae strains is also possible.

Recent studies have shown that overexpressing the ACCase enzyme increases malonyl-CoA availability in chloroplasts, which is an indicator of enhanced fatty acid production [39-41]. In microalgae, cultivation conditions with certain nutrient restrictions tend to increase ACCase expression [42]. Dunahay et al. [43] overexpressed ACCase in the diatom 
microalgae Cyclotella cryptica and resulted in a 2- to 3-fold increase in ACCase enzyme activity. However, there was only a slight increase in lipid production in this overexpression.

Although there was no significant increase in lipid accumulation after overexpression of ACCase, overexpression of numerous other enzymes involved in lipid production could enhance the lipid content of microalgae. Xue et al.[44] reported an increase in lipid content (2.5-fold) and enzyme activity without affecting cell growth on overexpression of the enzyme malate (target pathway: pyruvate metabolism) in the transgenic microalgae Phaeodactylum tricornutum. Furthermore, Hsieh et al. [45] overexpressed the enzymes glycerol-3-phosphate-acyl-transferase (GPAT), lysophosphate-atidic-acyl-transferase (LPAAT) and diacyl-glycerol-acyl-transferase (DGAT) (target pathway: Kennedy pathway) in Corynebacterium minutissimum UTEX 2219. The highest lipid content (2 folds) was found in the microalgae strain Chlorella minutissima transgenic. Thus, the enzyme multi-expression strategy can be used to increase lipid and biomass accumulation in microalgae. Several other studies carried out the expression of the enzyme 3-ketoacyl-acylcarrier protein synthase III (KASIII) which catalyzes the initial condensation reaction in fatty acid biosynthesis. Overexpression of this enzyme has been carried out for several plants [46].

Based on earlier understanding, it seems to be that this engineering can be carried out through a deeper understanding of the metabolic pathways and regulation of microalgae lipid biosynthesis, despite the fact that this strategy has been successful in several plants and microorganisms but has not been optimal in microalgae.

\subsection{Blocking of competitive metabolic pathways}

Blocking of competitive metabolic pathways such as carbohydrate and lipid catabolism is an effective strategy to increase lipid accumulation in microalgae [41]. Carbohydrate metabolism is an important pathway for the accumulation and storage of carbon in the form of starch present in many microalgae $[47,48]$. The suppression of starch metabolism will cause carbon to flow towards lipid biosynthesis. Breuer et al. [49] reported that an increase in TAG accumulation of up to $51 \%$ could be obtained using the starchless mutant Scenedesmus obliquus $(0.217 \mathrm{~g} / \mathrm{mol})$ compared to the wild type $(0.144 \mathrm{~g} / \mathrm{mol})$ under the same cultivation conditions. Breuer et al. found that there was no difference in photosynthesis in $S$. obliquus mutant and wild type and concluded that the mutation only affected cleavage under conditions of carbon availability in the metabolic pathway. Similar results were also reported by Li et al. [50]. The starchless Chlamydomonas mutant strain showed a 10-fold increase in TAG accumulation compared to the wild type. Starchless conditions in mutants can be achieved by deactivating ADP-glucose pyrophosphorylase which catalyzes reactions in starch metabolism. Chlorella pyrenoidosa mutant was also reported to increase fatty acid accumulation [51]. Wang et al [52] reported that an increase in TAG content could be obtained after deleting the AGPase gene (an essential enzyme in starch production).

Although inhibiting essential genes involved in starch synthesis can enhance lipid accumulation in huge quantities, it also causes a decrease in growth rate, which results in lower biomass productivity and, as a result, reduced lipid productivity in microalgae.

In addition to the suppression of starch metabolism, suppression of lipid catabolism is also one of the strategies used to increase lipid accumulation in microalgae. The mutant strain Thalassiosira pseudonana produced 3.5 folds higher lipid content after altered lipid catabolism by blocking the regulation of the multifunctional enzyme lipase/phospholipase/acyl transferase [53].

\section{Conclusion}

Two of the strategies in genetic engineering which can be used to increase microalgae lipid biosynthesis are overexpression of enzymes that play a role in lipid biosynthesis and blocking of competitive metabolic pathways. The strategy of overexpression of enzymes that play a role in lipid biosynthesis has been successfully studied in plants and microorganisms but has not been optimally carried out in microalgae. Overexpression of malate and multienzyme enzymes (GPAT, LPAAT and DGAT) can be used to increase microalgae lipid biosynthesis. The strategy of blocking competitive metabolic pathways can be carried out through suppression of starch metabolism and lipid catabolism. The strategy of blocking competitive metabolic pathways has been carried out in several microalgae and is effective for enhancing lipid biosynthesis. 


\section{Compliance with ethical standards}

\section{Acknowledgments}

I would like to express my deep gratitude to Professor Zulkarnain Chaidir, my research supervisors, for their patient guidance, enthusiastic encouragement and useful critiques of this research work.

\section{Disclosure of conflict of interest}

The authors declare that they have no known competing financial interests or personal relationships that could have appeared to influence the work reported in this paper.

\section{References}

[1] Brennan L, Owende P. Biofuels from microalgae-A review of technologies for production, processing, and extractions of biofuels and co-products. Renew Sustain Energ Rev. 2010; 14: 557-77.

[2] Yen H-W, Hu IC, Chen C-Y, Ho S-H, Lee D-J, Chang J-S. Microalgae-based biorefinery-From biofuels to natural products. Bioresour Technol. 2013; 135: 166-74.

[3] Ho S-H, Xiaoting Y, Tomohisa H, Jo-S C, Akihiko K. Perspectives on engineering strategies for improving biofuel production from microalgae - A critical review. Biotechnol Adv. 2014; 1-40.

[4] Doan QC, Moheimani NR, Mastrangelo AJ, Lewis DM. Microalgal biomass for bioethanol fermentation: Implications for hypersaline systems with an industrial focus. Biomass Bioenergy. 2012; 46: 79-88.

[5] Lam MK, LeeKT. Microalgae biofuels: A critical review of issues, problems and the way forward. Biotechnol Adv. 2012; 30: 673-90.

[6] Robbins MP, Evans G, Valentine J, Donnison IS, Allison GG. New opportunities for the exploitation of energy crops by thermochemical conversion in Northern Europe and the UK. Prog Energy Combust Sci. 2012; 38:138-55.

[7] Balat M, Balat H, OzC. Progress in bioethanol processing. Prog Energy Combust Sci. 2008; 34: 551-73.

[8] Parmar A, Singh NK, Pandey A, Gnansounou E, Madamwar D. Cyanobacteria and microalgae: a positive prospect for biofuels. Bioresour Technol. 2011; 102: 10163-72.

[9] Rashid N, Rehman MSU, Sadiq M, Mahmood T, Han J-I. Current status, issues and developments in microalgae derived biodiesel production. Sustain Energy Rev. 2014; 40: 760-778.

[10] Courchesne NMD, Parisien A, Wang B, Lan CQ. Enhancement of lipid production using biochemical, genetic and transcription factor engineering approaches. J of Biotech. 2009; 141: 31-41.

[11] World Bank. Focus B, Biofuels: Promise and Risks. 2008.

[12] Chisti Y. Biodiesel from microalgae. Biotechnol Adv. 2007; 25: 294-306.

[13] Demirbas A. Progress and recent trends in biofuels. Prog Energy Combust Sci. 2007; 33: 1-18.

[14] Knothe G. Biodiesel: current trends and properties. Top Catal. 2010; 53: 714-20.

[15] Makareviciene V, Skorupskaite V, Andruleviciute V. Biodiesel fuel from microalgae - promising alternative fuel for the future: a review. Rev Environ Sci Biotechnol. 2013; 12: 119-30.

[16] Schenk P, Thomas-Hall S, Stephens E, Marx U, Mussgnug J, Posten C, et al. Second generation biofuels: highefficiency microalgae for biodiesel production. Bioenergy Res. 2008; 1: 20-43.

[17] Sawayama S, Inoue S, Dote Y, Yokoyama S-Y. CO2 fixation and oil production through microalga. Energy Convers Manage. 1995; 36: 729-31.

[18] Durrett TP, Benning C, Ohlrogge J. Plant triacylglycerols as feedstocks for the production of biofuels. Plant J. 2008; 54: 593-607.

[19] Kirrolia A, Bishnoi NR, Singha R. Microalgae as a boon for sustainable energy production and its future research \& development aspects. Renew Sustain Energy Rev. 2013; 20: 642-56. 
[20] Singh B, Guldhe A, Rawat I, Bux F. Towards a sustainable approach for development of biodiesel from plant and microalgae. Renew Sust Energ Rev. 2014; 29:216-45.

[21] Klok AJ, Martens DE, Wijffels RH, Lamers PP. Simultaneous growth and neutral lipid accumulation in microalgae. Bioresour Technol. 2013; 134: 233- 43.

[22] Jiang Y, Yoshida T, Quigg A. Photosynthetic performance, lipid production and biomass composition in response to nitrogen limitation in marine microalgae. Plant Physiol Biochem. 2012; 54: 70-7.

[23] Converti A, Casazza AA, Ortiz EY, Perego P, Del Borghi M. Effect of temperature and nitrogen concentration on the growth and lipid content of Nannochloropsis oculata and Chlorella vulgaris for biodiesel production. Chem Eng Process: Process Intensif. 2009; 48: 1146-51.

[24] Singh P, Kumari S, Gulfhe A, Misra R, Rawat I, Bux F. Trends and novel strategies for enhancing lipid accumulation and quality in microalgae. Renew and Sustain Energ Rev. 2016; 55: 1-16.

[25] Tabatabaei M, Tohidfar M, Jouzani GS, Safarnejad M, Pazouki M. Biodiesel production from genetically engineered microalgae: future of bioenergy in Iran. Renew Sustain Energ Rev. 2011; 15: 1918-27.

[26] Illman AM, Scragg AH, Shales SW. Increase in Chlorella strains calorific values when grown in low nitrogen medium. Enzyme Microb Technol. 2000; 27(8): 631-5.

[27] Rao AR, Dayananda C, Sarada R, Shamala TR, Ravishankar GA. Effect of salinity on growth of green alga Botryococcus braunii and its constituents. Bioresour Technol. 2007; 98(3): 560-4.

[28] Lynn SG, Kilham SS, Kreeger DA, Interlandi SJ. Effect of nutrient availability on the biochemical and elemental stoichiometry in freshwater diatom Stephanodiscus minutulus acillario phyceae. J Phycol. 2000; 510-22.

[29] Guschina IA, Harwood JL. Lipids and lipid metabolism in eukaryotic algae. Prog Lipid res. 2006; 45: 160-86.

[30] Lv JM, Cheng LH, Xu XH, Zhang L, Chen HL. Enhanced lipid production of Chlorella vulgaris by adjustment of cultivation conditions. Bioresour Technol. 2010; 101: 6797-804.

[31] Dunahay TG, Jarvis EE, Zeiler KG, Roessler PG, Brown LM. Genetic engineering of microalgae for fuel production. Appl Biochem Biotechnol. 1992; 34 (35): 331-9.

[32] Apt KE, Kroth-Pancic PG, Grossman AR. Stable nuclea rtransformation of the diatom Phaeodactylum tricornutum. Mol Gen Genet. 1996; 252(5): 572-9.

[33] Tang DK, Qiao SY, Wu M. Insertion mutagenesis of Chlamydomonas reinhardtii by electroporation and heterologous DNA. Biochem Mol Biol Int. 1995; 36(5): 1025-35.

[34] Kumar SV, Misquitta RW, Reddy VS, Rao BJ, Rajam MV. Genetic transformation of the green alga Chlamydomonas reinhardtii by Agrobacterium tumefaciens. Plant Science. 2004; 166: 731-8.

[35] Dunahay TG. Transformationof Chlamydomonas reinhardtii with silicon carbide whiskers. Biotechniques. 1993; 15(3): 452-60.

[36] Kindle KL. High-frequency nuclear transformation of Chlamydomonas reinhardtii. PNAS. 1990; 87(3): 1228-32.

[37] Fan J, Andre C, Xu C. A chloroplast pathway for the denovo biosynthesis of triacylglycerol in Chlamydomonas reinhardtii. FEBS Letters. 2011; 585: 1985-91.

[38] Moellering ER, Benning C. RNA Interference Silencing of a Major Lipid Droplet Protein Affects Lipid Droplet Size in Chlamydomonas reinhardtii. Eukaryot Cell. 2010; 9(1): 97-106.

[39] Chao W, Xiong W, Dai J, Wu Q. Genome-based Metabolic Mapping and 13 C Flux Analysis Reveal Systematic Properties of an Oleaginous Microalga Chlorella protothecoides. Plant physiology. 2014; 114.

[40] Dal'Molin CG, Quek LE, Palfreyman RW, Nielsen LK. AlgaGEM-a genome-scale metabolic reconstruction of algae based on the Chlamydomonas reinhardtii genome. BMC Genomics. 2011; 12(Suppl4): S5.

[41] Chang RL, GhamsariL, Manichaikul A, Hom EFY, Balaji S, Fu W, et al. Metabolic network reconstruction of Chlamydomonas offers insight into light driven algal metabolism. Mol Syst Biol. 2011; 7: 518.

[42] Edwards JS, Ramakrishna R, Schilling CH, Palsson BO. Metabolic flux balance analysis. Metab Eng. 1999; 13-57.

[43] Gianchandani EP, Chavali AK, Papin JA. The application of flux balance analysis in systems biology. WIREs Syst Biol Med. 2010; 2. 
[44] Daniel S, Dennis V, George M. Church. Analysis of optimality in natural and perturbed metabolic networks. PNAS. 2002; 99(23): 15112-7.

[45] Tomer S, Omer B, Eytan R. Regulatory on/off minimization of metabolic flux changes after genetic perturbations. PNAS. 2005; 102(21): 7695-700.

[46] Dehesh K, Jones A, Knutzon DS, Voelker TA. Production of high levels of 8: 0 and 10:0 fatty acids in transgenic canola by overexpression of Ch FatB2, a thioesterase cDNA from Cuphea hookeriana. The Plant J. 1996; 9: 16772 .

[47] De Oliveira Dalmolin CG, Quek LE, Palfreyman RW, Brumbley SM, Nielsen LK. Ara GEM -aGenome-Scale Reconstruction of the Primary Metabolic Network in Arabidopsis thaliana. Plant Physiol. 2010; 152: 579-89.

[48] Selvarasu S, Karimi IA, Ghim GH, Lee DY. Genome-scale modelling and in silico analysis of mouse cell metabolic network. Mol Biosyst. 2010; 6: 152-61.

[49] Ma H, Sorokin A, Mazein A, Selkov A, Selkov E, Demin O, et al. The Edinburgh human metabolic network reconstruction and its functional analysis. Mol Syst Biol. 2007; 3: 135.

[50] Becker SA, Feist AM, Mo ML, et al. Quantitative prediction of cellular metabolism with constraint-based models: the COBRA Tool box. Nat Protoc. 2007; 2: 727-38.

[51] Ramazanov A, Ramazanov Z. Isolation and characterization of a starchless mutant of Chlorella pyrenoidosa STLPI with a high growth rate, and high protein and polyunsaturated fatty acid content. Phycol Res. 2006; 54: 2559.

[52] Wang ZT, Ullrich N, Joo S, Waffenschmidt S, Goodenough U. Algal lipid bodies: Stress induction, purification, and biochemical characterization in wild-type and starchless Chlamydomonas reinhardtii. Eukaryot Cell. 2009; 8: 1856-68.

[53] Hossain ABMS, Salleh A, Chowdhury P, Naqiuddin M. Biodiesel Fuel Production from Algae as Renewable Energy. Am J Biochem \& Biotech. 2008; 3(4): 250-4. 